\title{
Use of Google Translate in medical communication: evaluation of accuracy
}

\author{
(2) (1) $\Theta$ OPEN ACCESS
}

\author{
Sumant Patil senior clinical fellow, Patrick Davies consultant \\ Paediatric Intensive Care Unit, Nottingham Children's Hospital, Nottingham, UK
}

Communication is the cornerstone of medicine, without which we cannot interact with our patients. ${ }^{1}$ The General Medical Council's Good Medical Practice states that "Doctors must listen to patients, take account of their views, and respond honestly to their questions." ${ }^{2}$ However, we still often interact with patients who do not speak the local language.

In the United Kingdom most hospitals have access to translation services, but they are expensive and often cumbersome. A complex and nuanced medical, ethical, and treatment discussion with patients whose knowledge of the local language is inadequate remains challenging. Indeed, even in a native language there is an element of translation from medical to lay terminology.

We recently treated a very sick child in our paediatric intensive care unit. The parents did not speak English, and there were no human translators available. Reluctantly we resorted to a web based translation tool. We were uncertain whether Google Translate was accurately translating our complex medical phrases. ${ }^{34}$ Fortunately our patient recovered, and a human translator later reassured us that we had conveyed information accurately.

We aimed to evaluate the accuracy and usefulness of Google Translate in translating common English medical statements.

\section{Methods}

Ten commonly used medical statements were chosen by author consensus. These were translated via Google Translate to 26 languages. Translations only were sent to native speakers of each of these languages and translated back to English by them. The returned English phrases were compared with the originals and assessed for meaning. If translations did not make sense or were factually incorrect they were considered as wrong. Minor grammatical errors were allowed.

\section{Results}

Ten medical phrases were evaluated in 26 languages ( 8 Western European, 5 Eastern European, 11 Asian, and 2 African), giving 260 translated phrases. Of the total translations, 150 (57.7\%) were correct while 110 (42.3\%) were wrong. African languages scored lowest ( $45 \%$ correct), followed by Asian languages (46\%), Eastern European next with 62\%, and Western European languages were most accurate at $74 \%$. The medical phrase that was best translated across all languages was "Your husband has the opportunity to donate his organs" $(88.5 \%)$, while "Your child has been fitting" was translated accurately in only $7.7 \%$ (table $\Downarrow$ ). Swahili scored lowest with only $10 \%$ correct, while Portuguese scored highest at $90 \%$.

There were some serious errors. For instance, "Your child is fitting" translated in Swahili to "Your child is dead." In Polish "Your husband has the opportunity to donate his organs" translated to "Your husband can donate his tools." In Marathi "Your husband had a cardiac arrest" translated to "Your husband had an imprisonment of heart." "Your wife needs to be ventilated" in Bengali translated to "Your wife wind movement needed."

\section{Discussion}

Google Translate is an easily available free online machine translation tool for 80 languages worldwide. ${ }^{5}$ However, we have found limited usefulness for medical phrases used in communications between patients and doctor. ${ }^{367}$

We found many translations that were completely wrong. Google Translate uses statistical matching to translate rather than a dictionary/grammar rules approach, which leaves it open to nonsensical results. ${ }^{48}$

In today's world "just Google it" is considered to be the answer to everything, but for health related questions this should be treated with caution. ${ }^{9}$ Google Translate should not be used for 
taking consent for surgery, procedures, or research from patients or relatives unless all avenues to find a human translator have been exhausted, and the procedure is clinically urgent. We have, however, not assessed the accuracy of human translators, who cannot be assumed to be perfect and may be subject to confidentiality breaches.

We looked at translations from and to English only. Western European languages were the most accurately translated, implying a bias in translating algorithms towards those languages more commonly used in computing. Previous research has used one phrase, using the same algorithm to translate and retranslate, which is likely to increase the stated accuracy..$^{11}$

\section{Conclusion}

Google Translate has only $57.7 \%$ accuracy when used for medical phrase translations and should not be trusted for important medical communications. However, it still remains the most easily available and free initial mode of communication between a doctor and patient when language is a barrier. Although caution is needed when life saving or legal communications are necessary, it can be a useful adjunct to human translation services when these are not available.

Contributors: SP and PD shared the conception of the idea, sourcing suitable translators, and drafting the paper. PD is guarantor.

Funding: None.
Competing interests: We have read and understood the BMJ Group policy on declaration of interests and have no relevant interests to declare.

1 Brindley PG, Smith KE, Cardinal P, LeBlanc F. Improving medical communication: skills for a complex (and multilingual) clinical world. Can Respir J 2014;21:89-91.

2 General Medical Council. Good medical practice. GMC, 2013: paragraph 31. www.gmcuk.org/guidance/good_medical_practice.asp.

3 Börner N, Sponholz S, König K, Brodkorb S, Bührer C, Roehr CC. [Google Translate is not sufficient to overcome language barriers in neonatal medicine]. Klin Padiatr 2013;225:413-7.

4 Balk EM, Chung M, Chen ML, Trikalinos TA, Kong Win Chang L. Assessing the accuracy of Google Translate to allow data extraction from trials published in non-English languages. AHRQ Methods for Effective Health Care 2013 Report No 12(13)-EHC145-EF.

5 Google Translate. http://translate.google.com/about/int//en_ALL/.

6 Palluzi J. Results of using Google Translate for medical communication on the Android OS. iMedicalApps.com, 2010. www.imedicalapps.com/2010/07/results-of-using-googletranslate-for-medical-communication-on-the-android-os/.

7 Wade R. Try Google Translate to overcome language barriers. BMJ 2011;343:d7217. Gomes L. Google Translate tangles with computer learning. Forbes 2010 Jul 22. www. forbes.com/forbes/2010/0809/technology-computer-learning-google-translate.html.

9 Scullard P, Peacock C, Davies P. Googling children's health: reliability of medical advice on the internet. Arch Dis Child 2010;95:580-2.

10 Rubin M. Lost in translation. What happens when patients don't speak English? EMS World 2013;42:122.

11 Kaliyadan F, Gopinath Pillai S. The use of google language tools as an interpretation aid in cross-cultural doctor-patient interaction: a pilot study. Inform Prim Care 2010;18:141-3.

Accepted: 14 November 2014

\section{Cite this as: BMJ 2014;349:97392}

This is an Open Access article distributed in accordance with the Creative Commons Attribution Non Commercial (CC BY-NC 4.0) license, which permits others to distribute, remix, adapt, build upon this work non-commercially, and license their derivative works on different terms, provided the original work is properly cited and the use is non-commercial. See: http://creativecommons.org/licenses/by-nc/4.0/. 


\section{Table}

Table 1 | List of medical phrases translated via Google Translate

\begin{tabular}{|c|c|c|}
\hline Phrase translated & Sample or most common error & Percentage correct \\
\hline Your wife is stable & Your wife cannot fall over & 53.8 \\
\hline Your husband had a cardiac arrest & Your husband's heart was imprisoned & 53.8 \\
\hline Your husband had a heart attack & Your husband's heart was attacked & 73.1 \\
\hline Your wife needs to be ventilated & Your wife needs to be aired & 26.9 \\
\hline Your child's condition is life threatening & Your child's state is not life stopping & 69.2 \\
\hline Your child has been fitting & Your child has been constructing & 7.7 \\
\hline Your child will be born premature & Your child is sleeping early & 76.9 \\
\hline Your husband has the opportunity to donate his organs & Your husband is now ready to donate & 88.5 \\
\hline We will need your consent for operation & We need your consent for operating (such as machinery) & 61.5 \\
\hline Did he have high fever at home? & Your home temperature was high & 65.4 \\
\hline
\end{tabular}

